\title{
Surface engineering of a titanium alloy for tribological applications by nanosecond-pulsed laser
}

\author{
Daniel Kümmel $^{\text {a,c }}$, Dominic Linsler ${ }^{\text {b,c }}$, Reinhard Schneider ${ }^{\text {, }}$, Johannes Schneider ${ }^{\text {a,c, * }}$ \\ ${ }^{a}$ Institute for Applied Materials IAM, Karlsruhe Institute of Technology KIT, Kaiserstrasse 12, 76131, Karlsruhe, Germany \\ ${ }^{\mathrm{b}}$ Fraunhofer Institute for Mechanics of Materials IWM, Rintheimer Querallee 2a, 76131, Karlsruhe, Germany \\ ${ }^{\mathrm{c}}$ MicroTribology Center $\mu$ TC, Strasse am Forum 5, 76131, Karlsruhe, Germany \\ d Laboratory for Electron Microscopy LEM, Karlsruhe Institute of Technology KIT, Kaiserstrasse 12, 76131, Karlsruhe, Germany
}

Keywords:

Titanium alloys

Ti6Al4V

Surface engineering

Adhesive wear

\begin{abstract}
A B S T R A C T
In many applications, surface engineering is needed in order to overcome the poor wear properties of titanium alloys. A fiber laser was used in different operation modes for remelting a Ti6Al4V surface and subsequently smoothing it again, resulting in a smooth, glossy and crack-free surface. The laser treated surface was characterized by tribological experiments, nanoindentation and (transmission) electron microscopy and compared to samples treated by plasma nitridation and thermal oxidation. All surface treatments improved the tribological behavior of Ti6Al4V to different extents. Nanoindentation measurements showed no strict correlation of mechanical properties and tribological behavior. It is hypothesized that apart from mechanical properties, binding of titanium electrons by interstitials plays a role in the occurrence or absence of adhesive wear.
\end{abstract}

\section{Introduction}

Aviation is a vital part of our modern everyday lives, with both air travel and air freight transport increasing constantly throughout the last decades. Airline companies as well as customers ask for more fuel effi cient airplanes, which are therefore more cost efficient and environ mentally friendly.

Titanium alloys like the $\alpha / \beta$ alloy Ti6Al4V have high specific strengths and can be used in aerospace structures to reduce their weight, which helps in meeting these demands. While titanium alloys also offer further advantages like an excellent corrosion resistance, their tribo logical properties are poor [1]. Tribological systems using these alloys typically suffer from severe adhesive wear, leading to material transfer and high wear rates. Adhesive wear on titanium alloys can also hardly be counteracted by the use of conventional hydrocarbon based lubricants $[2,3]$.

In an earlier publication [4], we used a ns pulsed fiber laser to create linear, parallel channels on a Ti6Al4V surface. A distinct decrease in wear volume was reported, if laser surface texturing was performed in air with a sufficiently high packing density of channels. Textures itself had no major effect on the tribological results of this particular tribo system. It was concluded that the laser induced material change was dominant in increasing the wear resistance. Particularly, the laser remelted material was rich in interstitial oxygen and nitrogen and showed a purely martensitic $\alpha^{\prime}$ microstructure.

Since many aerospace components are mechanically loaded and can be critical concerning their fatigue resistance, surface textures pose a potential notch in these components and could reduce their fatigue life. Following previous results, laser treating the whole surface should result in similarly high wear resistance. However, laser surface remelting or laser nitriding has been reported to induce surface cracking [5 7], which would affect fatigue life as well. Remelting in argon atmosphere on the other hand avoids cracks, but only slightly improves tribological properties [8]. The concept of two step laser surface treatments has been proposed in literature $[9,10]$, which combined laser nitriding treatment with subsequent remelting. High power lasers were used for the described processes which yielded a partially dendritic microstructure including different titanium nitrides. The main effect of the second process step was a more homogeneous microstructure and hardness distribution in the nitridation layer.

By refining the process used earlier [4], a two step laser process was developed, with the aim of improving the wear resistance of Ti6Al4V without compromising the fatigue properties of potential aerospace components. The laser treatment consists of remelting the Ti6Al4V surface in air and subsequently smoothing it in argon atmosphere, which yields a smooth and crack free surface. Samples treated by this process

\footnotetext{
* Corresponding author. Institute for Applied Materials IAM, Karlsruhe Institute of Technology KIT, Kaiserstrasse 12, 76131, Karlsruhe, Germany. E-mail address: johannes.schneider@kit.edu (J. Schneider).
} 
Table 1

Laser parameters for the two process steps. Energy density was assessed from the diameter of $36.2 \mu \mathrm{m}$ for one single laser dimple. Power density was assessed from the width of $53 \mu \mathrm{m}$ of one smoothed track.

\begin{tabular}{lll}
\hline Parameters & Remelting & Smoothing \\
\hline Operation mode & pulsed & continuous wave $(\mathrm{CW})$ \\
Nominal laser power $[\mathrm{W}]$ & 9.1 & 10 \\
Pulse length $[\mathrm{ns}]$ & 26 & - \\
Pulse energy $[\mathrm{mJ}]$ & 0.091 & - \\
Average energy density/Fluence $\left[\mathrm{J} / \mathrm{cm}^{2}\right]$ & 8.8 & - \\
Average power density/Irradiance $\left[\mathrm{W} / \mathrm{cm}^{2}\right]$ & - & $0.45 \times 10^{6}$ \\
Pulse repetition rate $[\mathrm{kHz}]$ & 100 & $(20)$ \\
Scan speed $[\mathrm{mm} / \mathrm{s}]$ & 362 & 62 \\
Pulse spacing $[\mu \mathrm{m}]$ & 3.62 & - \\
Track spacing $[\mu \mathrm{m}]$ & 15 & 5 \\
Process repetitions $[-]$ & 2 & 2 \\
Atmosphere & air & argon \\
Scanning direction & unidirectional \\
\hline
\end{tabular}

were characterized by means of (transmission) electron microscopy, nanoindentation and tribological testing. For comparison, a plasma nitrided sample as well as a thermally oxidized sample were characterized by the same methods. Both of these treatments are known to increase the surface hardness of titanium alloys and have been suc cessfully used for improving their wear resistance $[11,12]$.

\section{Experimental}

\subsection{Materials}

Tribological testing was performed in linear reciprocating motion with $100 \mathrm{Cr} 6$ cylinders on Ti6Al4V plates. Ti6Al4V material was sup plied by ARA T (Dinslaken, Germany) in annealed state according to aerospace material specification AMS 4928. The non treated reference, thermally oxidized and laser treated samples showed an equiaxed microstructure and a macroscopic hardness of 325 HV3 in bulk. Plates of the dimensions $\varnothing 25 \mathrm{~mm} \times 8 \mathrm{~mm}$ were ground omnidirectionally on a Buehler PowerPro 4000 metallographic grinding machine (Esslingen, Germany) with a 240 grit SiC paper under constant water supply. Roughness of plates $R_{\mathrm{a}}$ was around $0.25 \mu \mathrm{m}$ after grinding. For the plasma nitridation treatment, a process related, different sample ge ometry was used. Discs of $\varnothing 50 \mathrm{~mm} \times 8 \mathrm{~mm}$ with a central mounting hole were ground centrically with a diamond wheel of grit D91, resulting in a roughness of $R_{\mathrm{a}} \approx 0.29 \mu \mathrm{m}$. Before tribological testing, rectangular plates of $15 \mathrm{~mm} \times 20 \mathrm{~mm}$ were cut from the plasma nitrided discs. Grains in bulk material of these samples were slightly elongated and the macroscopic hardness was $350 \mathrm{HV} 3$.
Cylinder rollers (SKF, Schweinfurt, Germany) of $\emptyset 10 \mathrm{~mm} \times 10 \mathrm{~mm}$ made from $100 \mathrm{Cr} 6$ steel were used as counter bodies without further preparation. The edges of the rollers have a logarithmic profile, which is supposed to minimize edge stresses in the bearing. In tribological testing, this facilitates the realization of a line contact. Cylinder surface roughness $R_{\mathrm{a}}$ was around $0.15 \mu \mathrm{m}$. The microstructure consists of annealed martensite, resulting in an average hardness of $750 \mathrm{HV} 3$.

All samples were cleaned in an ultrasonic bath using petroleum spirit and ethanol for $10 \mathrm{~min}$ each, directly before the experiments.

As lubricant, AeroShell Grease 33 (Shell, Hamburg, Germany) was used, which has a base oil viscosity of $14.2 \mathrm{~mm}^{2} / \mathrm{s}$ and $3.4 \mathrm{~mm}^{2} / \mathrm{s}$ at 40 ${ }^{\circ} \mathrm{C}$ and $100{ }^{\circ} \mathrm{C}$, respectively. Worked penetration according to ASTM D217 is 297, which corresponds to a NLGI consistency number of 12. AeroShell Grease 33 is a universal aerospace grease which contains corrosion/oxidation inhibitors and load carrying additives in a lithium complex thickened synthetic base oil.

Contacts were greased excessively, immediately before the experi ment, to ensure lubrication throughout the entire experiment.

\subsection{Methods}

Laser surface treatment was performed on a Piranha II marking laser system (ACSYS, Kornwestheim, Germany) with a maximum power of 20 W. As laser source, the Yb doped glass fiber laser SPI G4 Z Series EP (Southampton, United Kingdom) with a wavelength of $1060 \mathrm{~nm}$ was used, with the laser spot being moved across the surface by a Scanlab SCANcube 10 (Scanlab, Puchheim, Germany) galvanometer scanner. The used F theta lens (Linos, Gottingen, Germany) had a focusing length of $100 \mathrm{~mm}$. The laser can be operated in pulsed mode as well as in continuous wave (CW) mode. Due to laser pulses ranging in the ns regime, a considerable amount of material was not vaporized but only melted. In CW mode, it is assumed that almost no material was vapor ized at all. All laser parameters are given in Table 1. While the laser parameter study is beyond the scope of this paper, it should be stated that considerably different parameters easily led to formation of key holes and surface cracks during the smoothing process.

The laser surface treatment was conducted in two steps (see Fig. 1):

1. Remelting the surface in ambient air by close packing of laser tracks

2. Smoothing the surface with CW mode in argon atmosphere perpen dicular to remelting step.

Before starting the smoothing, the processing chamber was flooded with argon for $30 \mathrm{~s}$. A constant flow of $7.5 \mathrm{l} / \mathrm{min}$ was supplied during the whole smoothing process.

The surface after remelting and smoothing was crack free and had a

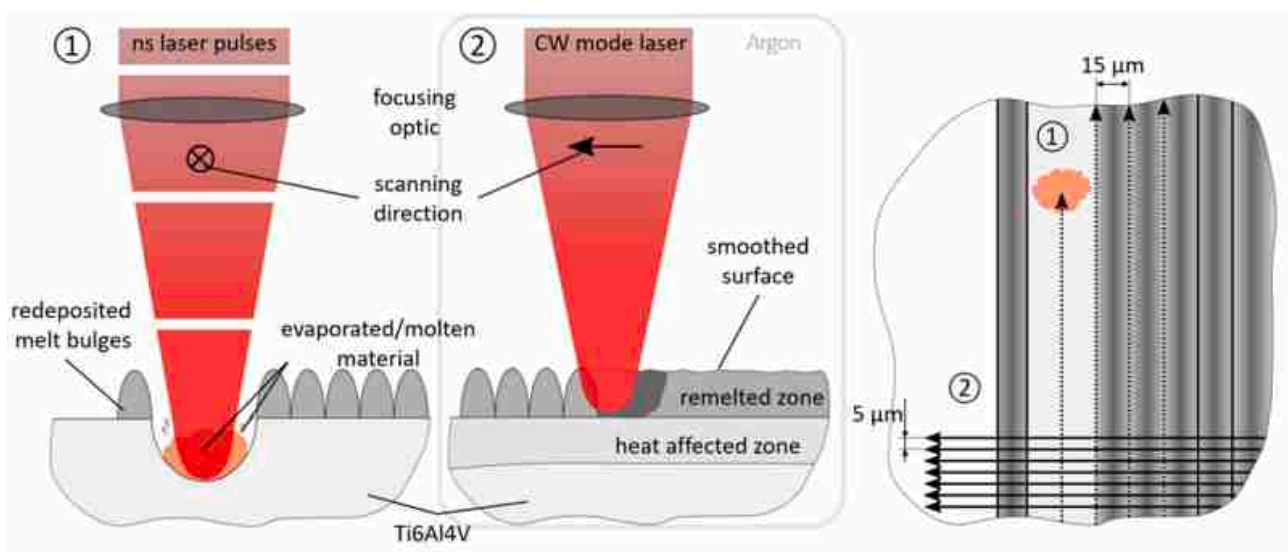

Fig. 1. Schematic of the two-step laser process. First step (1) was done in atmospheric air, second step (2) under argon-shielding gas. Right image shows a top view of the process. 


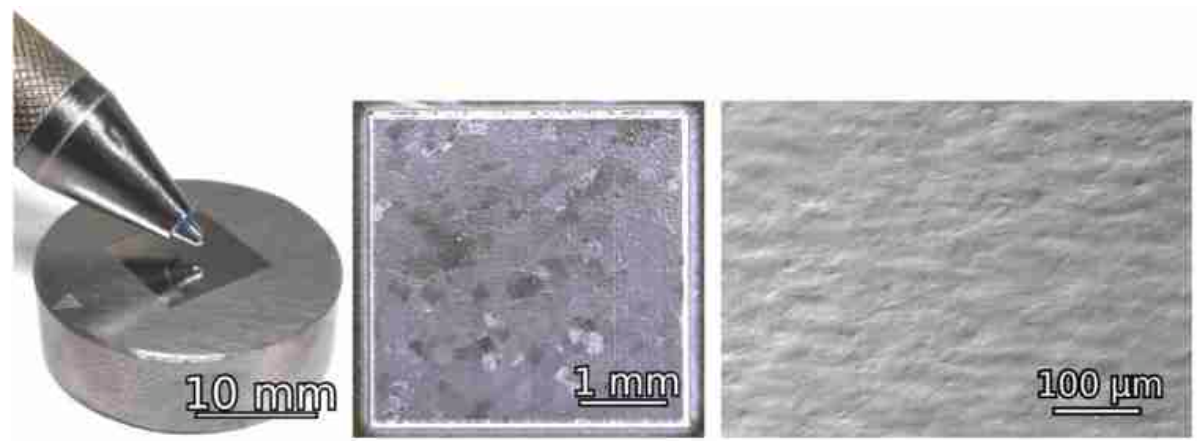

Fig. 2. Macroscopic (left), light microscopic (middle) and scanning electron image (secondary electron contrast, right) of the laser treated surface. Remelting direction is bottom-to-top, and smoothing direction is right-to-left, as shown in Fig. 1.

macroscopically shiny appearance and high reflectivity (Fig. 2). Details of roughness measurement procedure are given at the end of this section. Average roughness was around $R_{\mathrm{a}} \approx 0.2 \mu \mathrm{m}$ and hence only slightly smaller than for the ground reference surface $\left(R_{\mathrm{a}} \approx 0.25 \mu \mathrm{m}\right)$. Reflec tivity of surfaces can be better described by $R_{\mathrm{q}}$ and $R_{\Delta \mathrm{q}}$, however, which represent the root mean square of the roughness and slope, respectively [13]. These values were $R_{\mathrm{q}} \approx 0.25 \mu \mathrm{m}$ and $R_{\Delta \mathrm{q}} \approx 0.027$ compared to $R_{\mathrm{q}}$ $\approx 0.38 \mu \mathrm{m}$ and $R_{\Delta \mathrm{q}} \approx 0.087$ for the ground surface. If the remelted and ground surface was viewed from top and illuminated under certain an gles, a grain like structure was visible (Fig. 2, middle). Similar obser vations have been made by other researchers $[14,15]$. These structures are significantly larger than the actual grains visible by microstructure characterization, though, see Fig. 3.

There are many publications on achieving a thick, tribologically beneficial oxide layer on top of titanium by thermal oxidation [16 19]. However, the scope of this paper was to compare thermal oxidation to the laser remelting and smoothing treatment, which yields surface free from a thick oxide. Hence, a slightly different thermal oxidation treat ment was chosen where the thick surface oxide is removed after oxidation, like proposed by Bansal et al. [12]. Samples were placed in a Nabertherm muffle furnace (Lilienthal, Germany) for $2 \mathrm{~h}$ at $800{ }^{\circ} \mathrm{C}$ and subsequently cooled outside the furnace in air. The surface oxide spalled easily and was removed by light, omnidirectional grinding with 600 grit $\mathrm{SiC}$ paper under water supply. Therefore, the underlying diffusion zone was exposed and only covered by a $\mathrm{nm}$ thin passivation layer. Final roughness was around $R_{\mathrm{a}} \approx 0.18 \mu \mathrm{m}$.

Plasma nitridation was performed at Fraunhofer Institute for Surface Engineering and Thin Films IST (Braunschweig, Germany).

For nanoindentation measurements and microstructural character ization, samples were embedded in a polymeric resin mixed with conductive nickel filler. Metallographic cross sections were prepared by

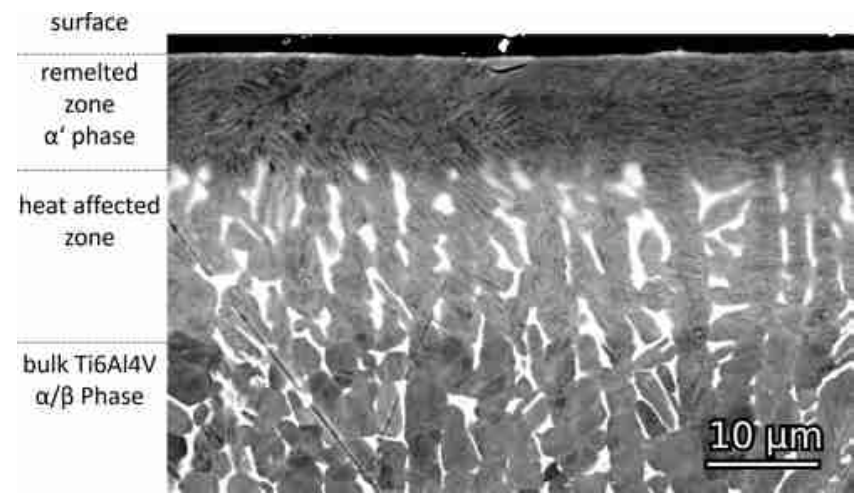

Fig. 3. Backscatter scanning electron image of a metallographically ground and polished cross section of a laser treated surface. The TEM foil was taken from the remelted zone at the surface. grinding up to 4000 grit SiC paper and subsequent polishing with $6 \mu \mathrm{m}$, $3 \mu \mathrm{m}$ and $1 \mu \mathrm{m}$ diamond paste. Final chemical mechanical polishing was done using a mixture of $90 \mathrm{ml}$ OP $\mathrm{U}$ suspension and $10 \mathrm{ml} 30 \% \mathrm{H}_{2} \mathrm{O}_{2}$.

Nanoindents were performed on a Hysitron TI 950 Triboindenter (Minneapolis, USA) with a modified Berkovich indenter tip and a load of $9 \mathrm{mN}$. Besides hardness, the reduced Young's modulus $\mathrm{E}_{\mathrm{r}}$ was deter mined by the method of Oliver and Pharr [20]. Indenter area function was calibrated before the measurements by indents in fused silica.

For the microstructural characterization of the treated surfaces, an FEI Helios Nanolab 650 Dual Beam Microscope (Hillsboro, Oregon, USA) was used. The electron beam was used for imaging surfaces and cross sections by scanning electron microscopy (SEM). By utilizing the focused ion beam, an electron transparent foil was prepared from the laser treated surface. For protection of sample from ion damage, two platinum layers were deposited before ion milling, first by electron beam, the second by ion beam. In order to achieve higher resolution, the foil was analyzed by (scanning) transmission electron microscopy (STEM/TEM) in an FEI Tecnai Osiris microscope at $200 \mathrm{kV}$ acceleration voltage. This microscope is equipped with a ChemiSTEM (FEI) detector, which was used to perform energy dispersive $\mathrm{X}$ ray spectroscopy (EDXS) to check for potential precipitates.

Tribological experiments were conducted on an Optimol SRV reciprocating tribometer (Munich, Germany). Sliding direction was chosen to be perpendicular to the remelting lines (laser treated sample) and grinding marks (plasma nitrided sample), respectively. Cylindrical counter bodies were oriented with their cylinder axis under $5^{\circ}$ to the sliding direction and parallel to the surface. Experimental parameters were kept constant at a normal load of $20 \mathrm{~N}$, frequency of $20 \mathrm{~Hz}$, stroke of $0.2 \mathrm{~mm}$ and duration of $60 \mathrm{~min}$. Atmosphere inside the tribometer was controlled to be $25 \pm 3{ }^{\circ} \mathrm{C}$ and $50 \pm 5 \% \mathrm{RH}$ during the experiments, the tribometer itself was set up in a temperature controlled laboratory. All tribological experiments were conducted twice. Tests were well reproducible and showed very similar results.

Topography was measured on a Sensofar Pl $\mu$ Neox (Barcelona, Spain) confocal microscope equipped with a 10x objective. All surface rough ness values correspond to measurements with this instrument. Topog raphy images of $1.27 \times 0.95 \mathrm{~mm}^{2}$ were acquired and profiles were evaluated for roughness values. Surfaces of reference, thermally oxidized and laser treated showed comparable roughness values in all directions. Plasma nitrided surface and counter bodies were measured perpendicular to grinding grooves. For each surface, an average of ten profiles was used. On samples with high wear, wear volumes were directly determined from the confocal image of the wear scars. For some samples with low wear, wear track depth was below the surface roughness and no wear volume could be calculated directly. However, a wear scar was visible in light microcopy (Keyence VHX 600D, Osaka, Japan) by a slight color change. The upper limit of wear volume was therefore estimated by the area of the wear scar multiplied by the arithmetic average height $R_{\mathrm{a}}$. 

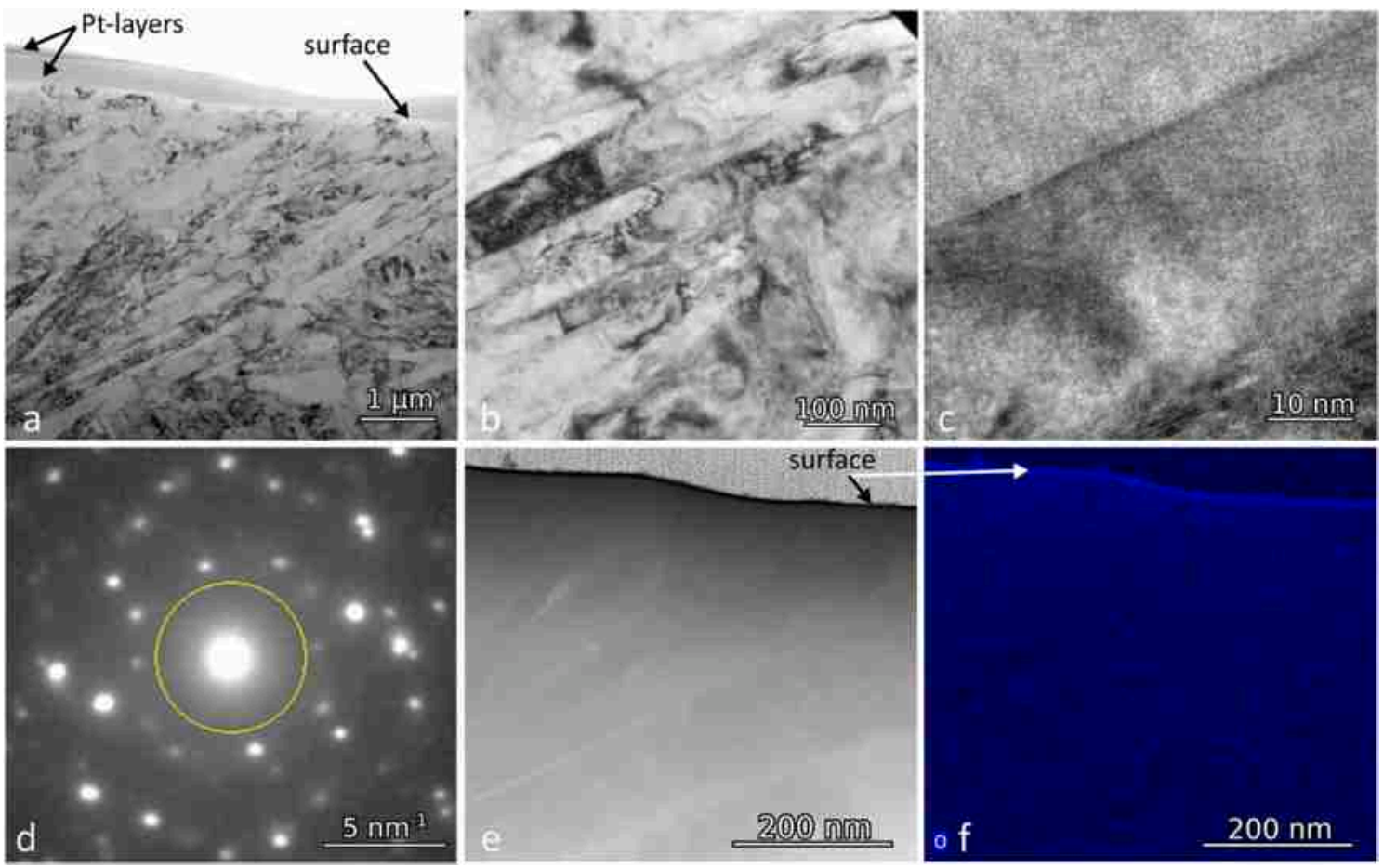

Fig. 4. TEM bright-field (a, b) and HRTEM (c) images showing the fine acicular martensitic microstructure of the top layer of the laser treated surface. SAED pattern (d) of the area shown in (b); the radial range of a spatial frequency of $3 \mathrm{~nm}{ }^{1}$ is marked with a circle. STEM HAADF image (e) of the region under investigation and corresponding EDXS map of the oxygen distribution (f). The laser smoothing step was performed perpendicular to the plane of the TEM foil.

\section{Results}

\subsection{Microstructural characterization of surfaces}

In order to characterize the treated surfaces, metallographic cross sections were prepared and analyzed by scanning electron microscopy. An image of the laser treated surface is shown in Fig. 3. In the lower part of the image, the Ti6Al4V $\alpha / \beta$ bulk material can be observed. The $\beta$ grains show bright in the electron backscatter image; darker areas are $\alpha$ grains. In the upper part of the image, an approximately $10 \mu \mathrm{m}$ thick layer can be seen, this is the material which has been melted by the laser. The microstructure is clearly different, and resembles a purely martensitic $\alpha^{\prime}$ phase of acicular morphology. High cooling rates as well as increased content in oxygen and nitrogen [4] favored the martensitic transformation over the equilibrium $\alpha / \beta$ crystallization [21 23]. Below the remelted zone is the heat affected zone of ca. $20 \mu \mathrm{m}$ thickness. This layer has not been melted, but was still subject to elevated temperature and high cooling rates. Therefore, grain boundaries of $\beta$ grain appear not as sharply defined as for the bulk material and a portion of the $\alpha$ grains seems martensitically transformed, indicated by the acicular morphology.

Fig. 4 shows a series of transmission electron microscopy images of increasing magnification taken from a TEM foil prepared from the remelted zone as indicated in Fig. 3. Evidently, both TEM bright field and high resolution TEM (HRTEM) images depict the martensitic microstructure in form of thin plates of $100200 \mathrm{~nm}$ average thickness. From the region visible in Fig. 4b, a selected area electron diffraction (SAED) pattern was recorded (cf. Fig. 4d), which exhibits the poly crystalline structure of the remelted material ( $\alpha^{\prime}$ phase). In this pattern, in the area of the marked circle with a radius of $3.0 \mathrm{~nm}^{-1}$ no Bragg

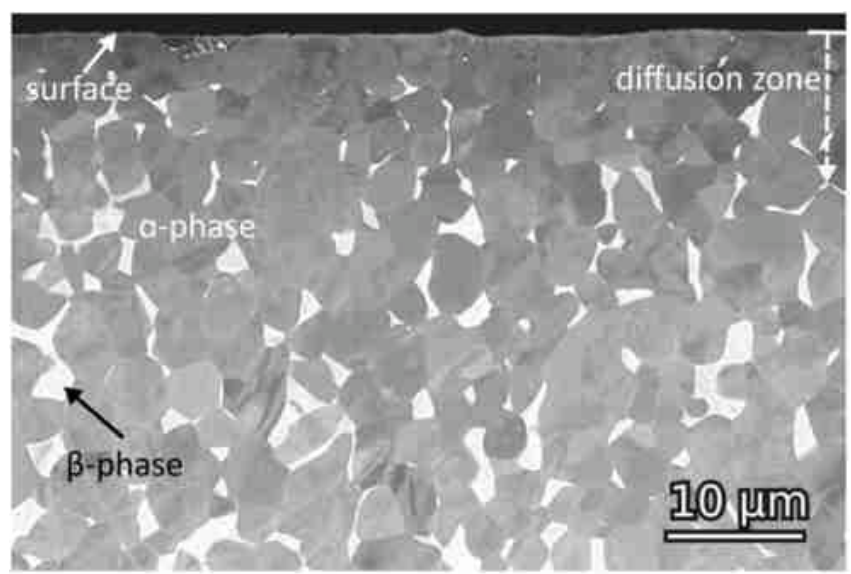

Fig. 5. Backscatter scanning electron image of a cross section of a thermally oxidized surface. Increased oxygen content near the surface is stabilizing the $\alpha$-phase and leading to a reduction of the bright $\beta$-phase.

reflections can be seen. This is an indication that titanium oxide pre cipitates are absent in the remelted material, since both types of oxides with tetragonal crystal structure, namely rutile and anatase, would show intense reflections at $3.078 \mathrm{~nm}^{-1}$ (110 reflex of rutile) and $2.844 \mathrm{~nm}^{-1}$ (101 reflex of anatase), respectively. In addition, the remelted zone was also investigated by combined STEM/EDXS analyses. Typical results are given in Fig. 4, where the STEM image (Fig. 4e) taken with the high angle annular dark field (HAADF) detector does not reveal strong local contrast variations. This hints at the absence of oxide precipitates, too, because for constant TEM foil thicknesses the HAADF signal 


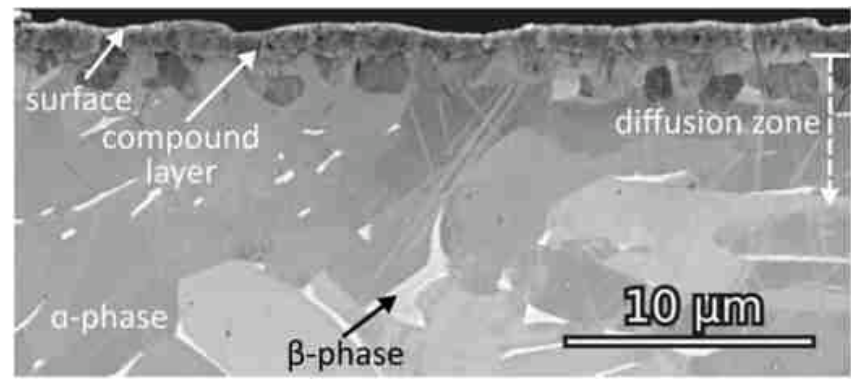

Fig. 6. Backscatter electron image of a cross section of a plasma nitrided surface. A compound layer was formed which is followed by a diffusion zone.

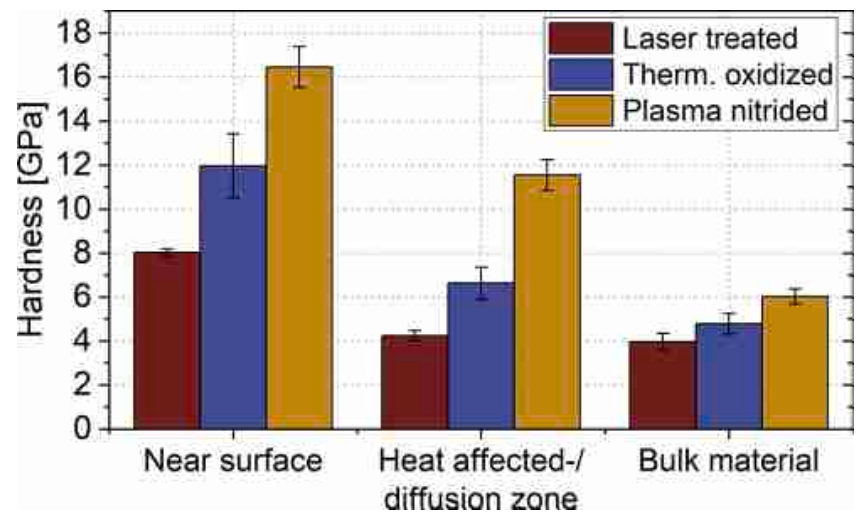

Fig. 7. Hardness values measured by nanoindentation, mean value and standard deviation of at least four measurements.

generally exhibits atomic number (Z) contrast. Therefore, if there were $\mathrm{TiO}_{2}$ particles within the Ti matrix, they would appear darker due to the difference $\Delta \mathrm{Z} \approx 9$ in the mean atomic number. Moreover, the EDXS map (cf. Fig. 4f) of the oxygen distribution proves in a direct manner that no oxide particles are present below the surface. However, the oxygen map clearly shows an oxide passivation with a thickness of approximately 10 $\mathrm{nm}$ on top of the remelted material.

We showed before that laser melted material is rich in oxygen and nitrogen [4]. However, no oxide particles below the surface of the laser treated material could be identified by different electron microscopic techniques. This is in line with previous research on oxygen rich tita nium [24] and can be explained by the high solubility of up to 33 at $\%$ oxygen in titanium [25].

A cross section of a thermally oxidized sample is shown in Fig. 5. It is evident that the fraction of bright $\beta$ grains decreases to almost zero to wards the surface. This is due to the $\alpha$ stabilizing characteristic of interstitial oxygen in titanium [22].

The cross section of the plasma nitrided surface (Fig. 6) displays a more heterogeneous structure. In contrast to the other two samples, $\alpha$ and $\beta$ grains are slightly elongated in bulk material shown in the lower part of the image. On the very surface, a compound layer of approxi mately $1.2 \mu \mathrm{m}$ thickness was formed. Below this layer, a $510 \mu \mathrm{m}$ thick diffusion zone follows. At the top of the diffusion zone, $\alpha$ grains appear to be globular, different from the bulk, possibly due to recrystallization. Several researchers described this zone and drew a connection to an aluminum enrichment below the compound layer [26,27]. Aluminum both stabilizes and strengthens the $\alpha$ phase of titanium.

\subsection{Nanoindentation}

Positions for nanoindents were chosen according to the microstruc ture characterization shown above; the hardness values are given in Fig. 7. Indents were imaged by atomic force microscopy to check for

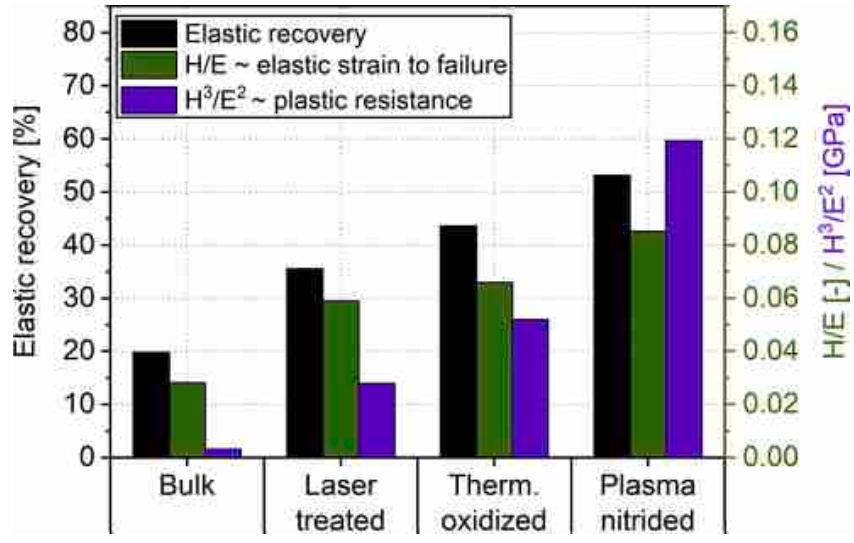

Fig. 8. Different relations drawn from the 'near surface' nanoindents, describing the mechanical behavior of treated samples.

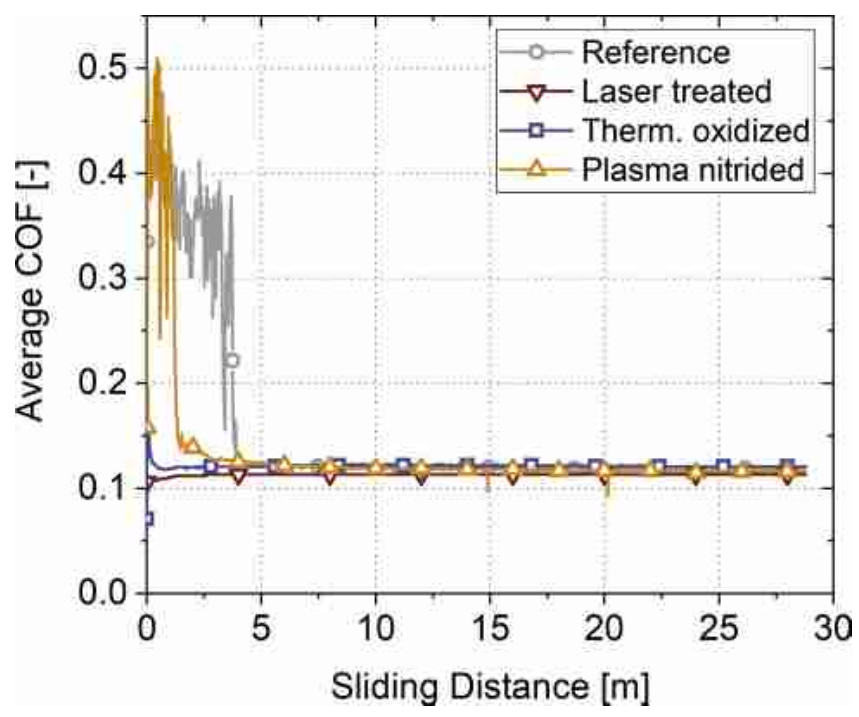

Fig. 9. Average coefficient of friction as a function of sliding distance for different types of surface treatments in comparison with the nontreated reference.

pile up around the indents. No significant amount of pile up was found.

For the laser treated sample, indents were placed in the remelted zone, $2 \mu \mathrm{m}$ below the surface. Further indents were done ca. $15 \mu \mathrm{m}$ and $52 \mu \mathrm{m}$ below the surface in the heat affected zone and bulk material, respectively. The results show that the remelted zone was substantially hardened to $8.03 \mathrm{GPa}$ by the laser treatment, the hardness being increased by around a factor of two compared to bulk material (3.96 GPa). In contrast, the heat affected zone showed no substantial hard ening with a hardness of $4.24 \mathrm{GPa}$.

The thermally oxidized sample was indented $2 \mu \mathrm{m}$ below the surface, $22 \mu \mathrm{m}$ below, and in the bulk material. While the average hardness of bulk material is slightly higher than that of the laser treated sample, their standard deviations do overlap and are considered comparable. The indents near the surface show that the hardness is increased to $11.96 \mathrm{GPa}$, an even stronger increase than in the laser treated sample.

Indents in the plasma nitrided sample were placed in the thin com pound layer ( $1 \mu \mathrm{m}$ from the surface), just below in the diffusion zone (1.8 $\mu \mathrm{m}$ from the surface), and in the bulk material (ca. $25 \mu \mathrm{m}$ from the surface). The bulk material of this sample already showed higher hardness compared to the other two samples, which is consistent with the macroscopic hardness measurements. This might be caused by the different bulk microstructure. It is evident that this sample shows the highest hardness at all depths compared to the other two samples. 


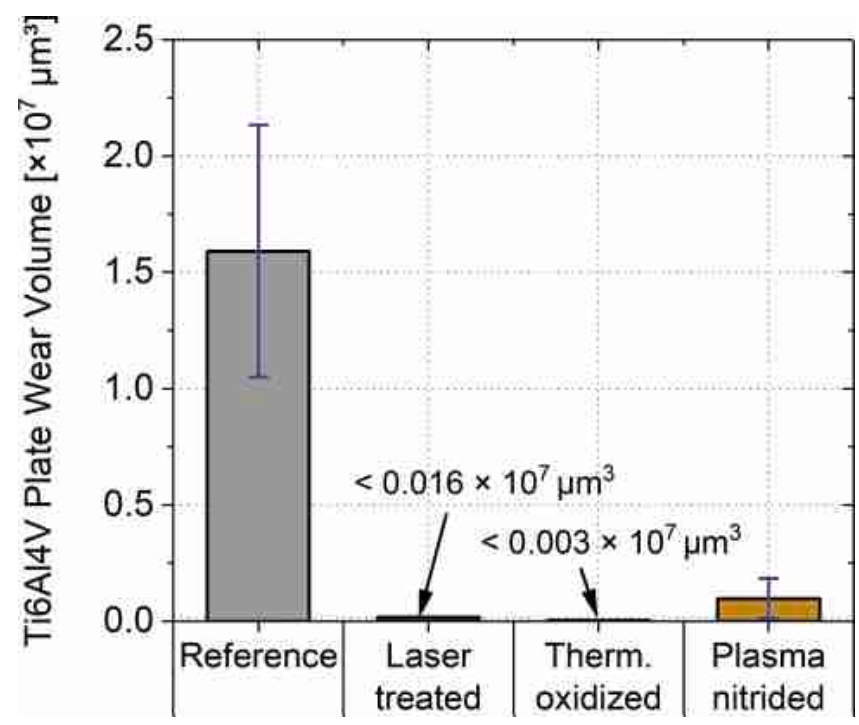

Fig. 10. Wear volume of Ti6Al4V plates with different surface treatments.

Additional characteristics were drawn from nanoindentation data and are shown in Fig. 8. For correlation with tribological properties, Leyland and Matthews [28] suggested the ratio of H/E which describes the 'elastic strain to failure' of a material or coating, whereas $\mathrm{H}^{3} / \mathrm{E}^{2}$ can be used as an indicator for its resistance to plastic deformation. From single load displacement curves, the percentage of elastic energy recovered from indentation could be calculated.

Only small elastic recovery of $20 \%$ was measured for the Ti6Al4V bulk material. Higher ratios were found for the laser treated (36\%) and thermally oxidized sample (44\%), with the highest value being that of the plasma nitrided sample (53\%). Similar qualitative trends can be observed for the other two characteristics, while the increase of $\mathrm{H}^{3} / \mathrm{E}^{2}$ is more pronounced than that of the $\mathrm{H} / \mathrm{E}$ value.

\subsection{Tribological properties}

Average coefficients of friction over sliding distance for all samples in contact with the $100 \mathrm{Cr} 6$ counter body are given in Fig. 9. The non treated reference showed a pronounced running in behavior with high and unsteady initial coefficients of friction of up to 0.5. After several meters of sliding distance, a transition occurred to a lower, constant coefficient of friction of 0.13 . The duration of this running in period varied significantly between test repetitions. For the plasma nitrided sample, a similar course in friction could be measured, while the running in period was considerably shorter compared to the non treated reference. In contrast, samples which were thermally oxidized or laser treated did not show a running in period but displayed a constant co efficient of friction of 0.13 from the beginning of the experiment. At the end of the experiments, all samples showed a similar coefficient of friction of around 0.13, regardless of their surface treatment or pre ceding running in period.

Wear volume of Ti6Al4V plates was determined after the experi ments and is shown in Fig. 10. It is evident that the non treated reference shows high wear compared to all other samples. The plasma nitrided sample showed much less wear, but the wear scars were still clearly measurable by confocal microscopy. Since for the thermally oxidized sample and laser treated sample, wear depth was below the surface roughness, only an upper limit of wear can be given, calculated as described in the methods section. Wear was reduced by more than two orders of magnitude by laser remelting and smoothing or thermal oxidation. The upper limit of the thermally oxidized sample is even lower because both the surface roughness and the area of its wear scars were smaller compared to the laser treated.

Fig. 11 shows confocal images of representative wear scars for all differently treated surface. Severe wear is apparent for the reference surface, with a high wear depth of up to $20 \mu \mathrm{m}$ and clear signs of ad hesive wear such as deep pits caused by material transfer onto the counter body. Similar characteristics can be seen for the center of the wear scar on the plasma nitrided sample. It also appears as adhesive type wear with deep craters where material was removed from the surface and transferred to the counter body. While the area of the wear scar is much smaller, wear depth is similar to reference, however.
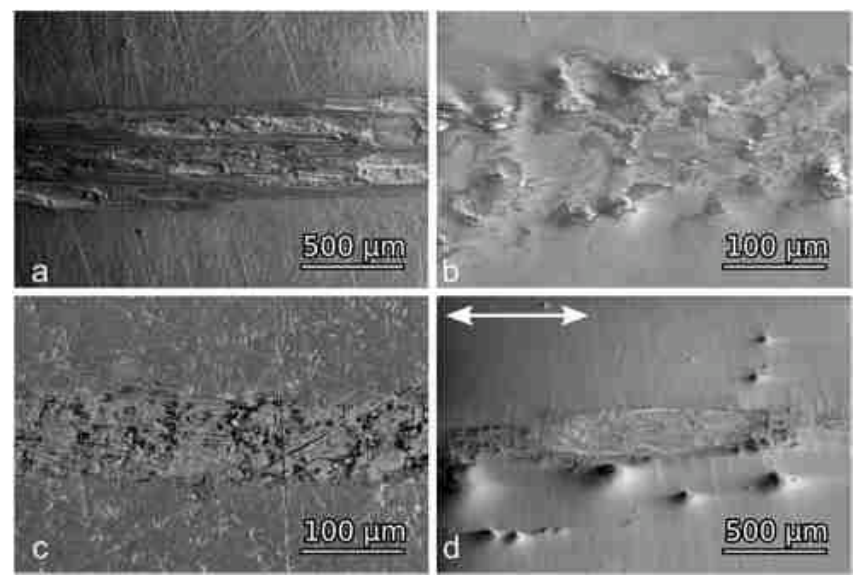

Fig. 12. SEM images (secondary electron contrast) of wear scars of the untreated reference (a), laser treated (b), thermally oxidized (c) and plasma nitrided (d) surface. Note the higher magnification in (b) and (c).

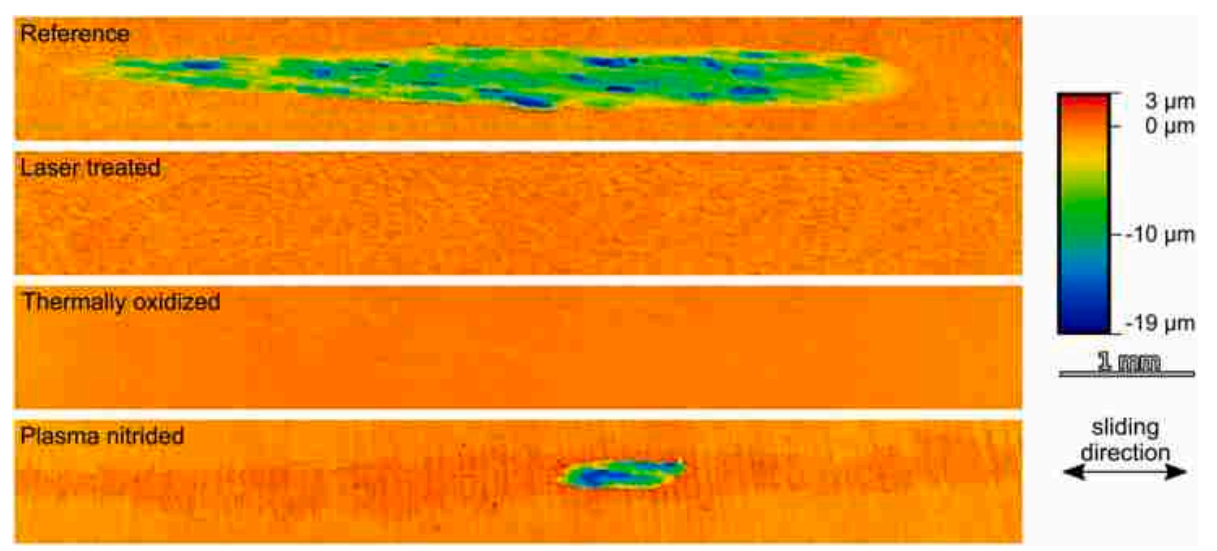

Fig. 11. Confocal images of representative wear scars on all different surfaces. Scale bar and z-scale are valid for all images. 

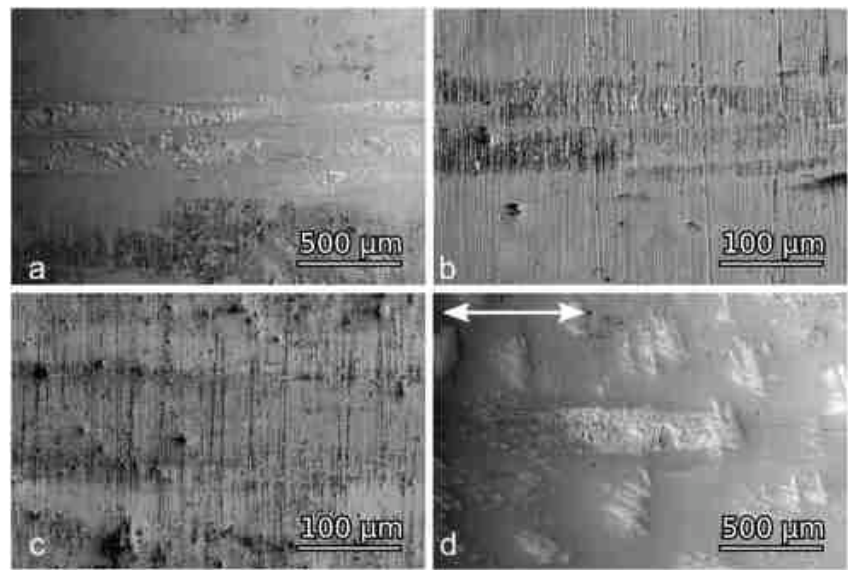

Fig. 13. SEM images (secondary electron contrast) of wear scars on 100Cr6 counter bodies. Counter bodies were tested against reference (a), laser treated (b), thermally oxidized (c) and plasma nitrided (d) surface. Material transfer can be observed in (a) and (d). Note the higher magnification in (b) and (c).

Interestingly, material was removed from depths of up to around $19 \mu \mathrm{m}$, where material was unaffected by plasma nitridation, compare Fig. 6 . Due to the logarithmic profile of the cylindrical counter body, wear occurred preferentially in the middle of the wear track. Confocal images for thermally oxidized and laser treated samples show that wear depth is below surface roughness and no wear scar can be seen or measured.

Wear mechanisms can also be seen clearly by comparing SEM images of the wear scars on Ti6Al4V (Fig. 12). Different magnifications were chosen in order to depict the surface changes in the wear scars. Wear scars of reference (a) and plasma nitrided surface (d) show clear signs of adhesive wear and wear particles on the surface. On the other hand, wear scars of the laser treated (b) and thermally oxidized (c) sample are significantly smaller. Only light abrasive grooves and some surface smoothing is apparent. It can be further seen that the wear scar area of the laser treated sample is slightly larger than that of the thermally oxidized sample.

In the same manner, SEM images of wear scars on $100 \mathrm{Cr} 6$ counter bodies are presented in Fig. 13. On the counter bodies which slid against the laser treated (b) and thermally oxidized sample (c), only slight abrasive marks can be seen. Conversely, counter bodies of reference (a) and plasma nitrided (c) show distinct signs of adhesive material transfer, which corresponds to the removed material in the wear scars of the base body (Fig. 12).

\section{Discussion}

\subsection{Hardening mechanisms}

First, the hardening mechanism of the plasma nitrided sample shall be discussed. This is the only sample investigated, where a compound layer has formed on the surface. Since there is only one layer visible (Fig. 6), it can be hypothesized that it consists mainly of $\mathrm{Ti}_{2} \mathrm{~N}$ [5]. Also, both the thickness and hardness of the layer agree well with values re ported for $\mathrm{Ti}_{2} \mathrm{~N}$ before $[5,29]$. Below the compound layer, hardening can be explained by solid solution strengthening of $\mathrm{Ti}$ [30] as well as the stabilization of the harder $\alpha$ phase by nitrogen [22], resulting in a reduced $\beta$ fraction below the compound layer.

Similar to the diffusion zone of the plasma nitrided case, the ther mally oxidized sample showed solid solution strengthening and stabili zation of $\alpha$ phase. No layered structure or compound layers were visible (Fig. 5), therefore a gradient in hardness is expected and has been re ported for similarly oxidized Ti6Al4V before [11].

In the laser treated sample, significant hardening occurred in the remelted layer which was mainly caused by the increased oxygen content as a result of the fast oxygen diffusion in the liquid phase. TEM results demonstrate that no precipitates are present in the subsurface material and the hardening is therefore caused by solid solution of ox ygen (Fig. 4). On the other hand, the heat affected zone was not hard ened. In contrast to martensite in steel, the martensitic transformation in titanium only offers mild strengthening [22,31]. High cooling rates led to a partially martensitic microstructure but to no appreciable hard ening. The heat affected zone remained solid at all times during the process, and did not acquire significant amounts of additional oxygen. Opposed to the other two processes, the exposure time to heat during the laser process was short and no significant diffusion could take place in the solid phase, thus no hardness increase in the heat affected zone was measurable by nanoindentation.

\subsection{Wear behavior}

Surfaces of bulk, thermally oxidized and plasma nitrided samples were all ground and are therefore similar in topography. Laser treated samples differ in topography but are comparable to the others, at least with respect to $R_{\mathrm{a}}$. Influence of topography will not be further discussed, because it was shown before that laser textures had no major influence on tribology if laser induced material changes were excluded [4].

The used lubricant, Aeroshell Grease 33, is a fully formulated grease containing several additives. By reproducing wear results with an additive free base oil of similar viscosity, we showed before that these additives play no major role in the change in wear behavior on laser treated Ti6Al4V [4]. Therefore, influence of lubricant additives will not be further reviewed here.

From the wear scar (Fig. 11), it can be clearly seen that the reference sample suffered from severe adhesive wear, as it would be expected for the tribological behavior of Ti6Al4V [1]. It seems surprising that the plasma nitrided surfaces showed similar wear characteristics, even though to a lower extent. This may be connected to the formation of the compound layer. $\mathrm{Ti}_{2} \mathrm{~N}$ can be viewed as a nitride ceramic which is hard (16.45 GPa) and supposedly quite brittle. With a hardness difference of 4.91 GPa, the underlying diffusion zone is significantly softer. In tribo logical contact, normal and tangential loads could lead to fracture of the compound layer, which is not sufficiently supported by the substrate [32]. This is commonly referred to as the 'eggshell' or 'thin ice' effect [33]. Material from depths of up to $19 \mu \mathrm{m}$ was removed in tribological contact, i.e. the separation of material occurred in the bulk which was unaffected by plasma nitridation. It is reasonable to assume that this wear event appeared after the initial fracture of the compound layer and during the initial running in of the experiment. After the formation of this wear scar, contact area was larger and contact stresses were not high enough to lead to further fracture of the compound layer.

Surface hardness is in many cases believed to increase the wear resistance of materials or improve the tribological properties in general [28]. Especially for titanium alloys, hardness is believed to be crucial since it limits plastic deformation and therefore junction growth in tribological contact $[34,35]$. In turn, this will decrease the amount of adhesion and consequently adhesive wear. The derived measures of $\mathrm{H} / \mathrm{E}, \mathrm{H}^{3} / \mathrm{E}^{2}$ and the amount of elastic recovery were calculated in order to describe the mechanical properties of the layers more accurately with respect to plastic deformation. As for hardness, a trend from bulk ma terial to the plasma nitrided sample could be drawn in Fig. 8. Neither hardness, nor any of the derived characteristics can correctly predict the wear behavior, however, since both samples with the extreme values (bulk, plasma nitrided) showed adhesive wear while the intermediate values (thermally oxidized, laser treated) did not. In summary, comparing the wear results in Fig. 10 to the nanoindentation data shown in Figs. 7 and 8, it becomes evident that none of the characteristics drawn from nanoindentation can completely describe the wear behavior of the treated surfaces.

Furthermore, note that, even if the compound layer caused by plasma nitridation is considered to be removed by fracture, the diffusion 

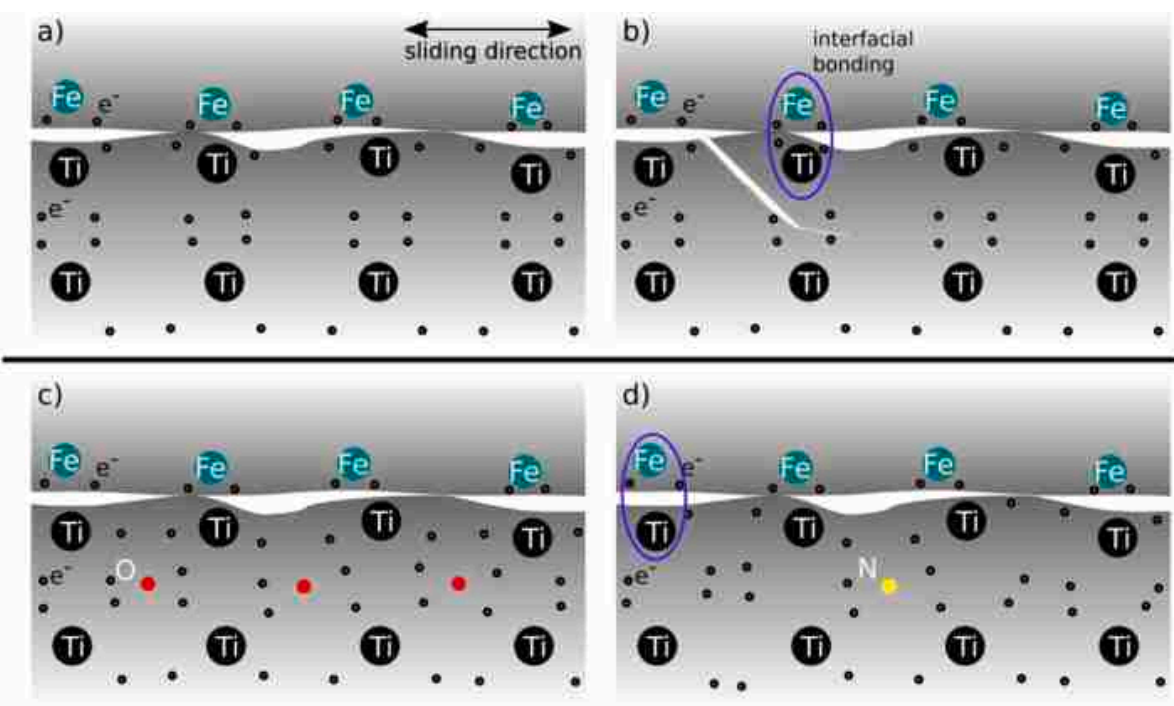

Fig. 14. Schematic representation of the effect of interstitial solutes in titanium on its tribological behavior, extended from Ref. [4]. Unbound electrons of the titanium lattice can interact freely with the counter body, leading to adhesion and adhesive wear (a, b). Interstitial oxygen changes the electron density around titanium atoms, saturates electronic bonds and therefore prevents adhesive wear (c). If the compound layer fractures and interstitial concentration of nitrogen is lower in the diffusion zone of the plasma nitrided sample than the concentration of oxygen in the laser treated or thermally oxidized sample, more free electrons are available to interact with the counter body (d). Hence, adhesive wear can be seen in the wear scar of the plasma nitrided sample. Titanium surface oxide is assumed to be removed in tribological contacts [35]; lubrication is not shown for simplification. zone of this sample still shows hardness which is higher than the laser treated and comparable to the thermally oxidized sample (around 12 GPa, see Fig. 7). Consequently, it is unexpected that adhesive wear still prevails for this sample. The question arises, why the laser treated sur face shows no adhesive wear, despite its lower hardness. Results sug gests that other mechanisms apart from plastic deformation are involved in the wear behavior of the surface treated Ti6Al4V samples.

Besides other aspects, the electronic structure is considered to in fluence the adhesive properties of solids [36,37] and titanium in particular [38,39]. Titanium is intensely strengthened by interstitial solutes [30], with the strengthening power of nitrogen in titanium being usually regarded around twice as strong as the one of oxygen [40 42]. Considered that the peak hardness of thermally oxidized sample and the diffusion zone of the plasma nitridation are similar, it follows that the concentration of oxygen should be double that of nitrogen.

Apart from the interstitial induced lattice strain, the interactions of dislocation cores with interstitials are cause for the intense solid solution strengthening seen in titanium $[43,44]$. On the atomic level, interstitial elements are chemically bound to the titanium lattice atoms, which was shown by experiments $[44,45]$ and later by simulations $[44,46]$. In terstitials shift electronic charge density from titanium atoms to inter stitial sites $[47,48]$ and therefore make the titanium surfaces chemically less adhesive. This led to the model conception of the effect of altered electronic structure on tribology of titanium shown in Fig. 14. A similar mechanism has been observed by first principles calculations for the adhesion of $\alpha$ iron and (cerium doped) tungsten carbide [49].

Assuming that each interstitial atom binds electrons of its sur rounding lattice atoms, there are more unbound atoms in the diffusion layer of the plasma nitrided than in the thermally oxidized sample of the same hardness. Free electrons of titanium atoms could interact more easily with the counter body and lead to adhesion and consequently adhesive wear, see Fig. 14.

Chemical analysis of the treated surfaces is subject of ongoing research to further support this hypothesis.

\section{Conclusion}

A surface treatment process for Ti6Al4V was presented which con sists of remelting and subsequently smoothing the surface by a fiber laser in ns pulsed and CW operation mode, respectively. It was used to improve the poor tribological properties of Ti6Al4V while minimizing the presumed impact of surface treatment on fatigue resistance. Tribo logical tests were performed in reciprocating sliding with a grease lubricated line contact. Samples were further characterized by nanoindentation and (transmission) electron microscopy. For compari son, plasma nitrided and thermally oxidized samples were tribologically tested and characterized by the same methods.

Investigation of the laser treated samples revealed a smooth and glossy surface which was free from cracks. Microstructure consisted of an approximately $10 \mu \mathrm{m}$ thick remelted, martensitic top layer which was significantly hardened by solid solution of oxygen. Plasma nitrided and thermally oxidized surfaces were hardened even stronger, especially with the plasma nitridation leading to a thin compound layer on the surface.

As expected for a titanium alloy, non treated reference samples showed severe adhesive wear. For laser treated and thermally oxidized samples wear was below the surface roughness and could only be esti mated. It was reduced by at least two orders of magnitude compared to reference. The plasma nitrided sample showed higher amount of wear, but wear was still significantly reduced compared to reference. Small amounts of adhesive wear, likely caused by preceding fracture of the compound layer, were identified.

Due to the wear behavior of the hard plasma nitrided sample, it became evident that there was no strict correlation of mechanical behavior during nanoindentation and tribological properties for the investigated surface treatments. Possibly, there are further 'chemical' effects involved in the tribological contacts, explained by the binding of titanium valence electrons by interstitials.

No significant difference in tribological behavior between the laser treated and thermally oxidized samples became apparent in the con ducted experiments. Yet, the laser treatment does offer some advantages over the thermal oxidation from a technological or industrial point of view. For small batch sizes, a laser treatment may offer significant time saving over a classical furnace treatment. Furthermore, considering fa tigue loads on e.g. aircraft components, it may be advantageous to selectively treat tribologically loaded surfaces of components and omit surfaces which could be critical with respect to fatigue. Implementation of this surface treatment method to laser based additive manufacturing processes such as selective laser melting could also be feasible.

\section{Declaration of competing interest}

The authors declare that they have no known competing financial interests or personal relationships that could have appeared to influence the work reported in this paper. 


\section{CRediT authorship contribution statement}

Daniel Kümmel: Conceptualization, Methodology, Validation, Formal analysis, Investigation, Writing original draft, Visualization. Dominic Linsler: Methodology, Validation, Investigation, Writing review \& editing, Resources. Reinhard Schneider: Methodology, Formal analysis, Investigation, Resources, Writing review \& editing. Johannes Schneider: Conceptualization, Methodology, Writing re view \& editing, Project administration, Funding acquisition.

\section{Acknowledgements}

This work was funded by the German BMWi within the scope of the project FAWIBO (20Y1505C), headed by Liebherr Aerospace.

\section{References}

[1] Budinski KG. Tribological properties of titanium alloys. Wear 1991;151(2):203-17. https://doi.org/10.1016/0043-1648(91)90249-T.

[2] Hsu SM. Boundary lubrication of materials. MRS Bull 1991;16(10):54-8. https:// doi.org/10.1557/S0883769400055846.

[3] Rabinowicz E. Boundary lubrication of titanium. 5th World Petroleum Congress; 1959. p. 319-30.

[4] Kümmel D, Hamann-Schroer M, Hetzner H, Schneider J. Tribological behavior of nanosecond-laser surface textured Ti6Al4V. Wear 2019;422-423:261-8. https:// doi.org/10.1016/j.wear.2019.01.079.

[5] Zhecheva A, Sha W, Malinov S, Long A. Enhancing the microstructure and properties of titanium alloys through nitriding and other surface engineering methods. Surf Coating Technol 2005;200(7):2192-207. https://doi.org/10.1016/j. surfcoat.2004.07.115.

[6] Perry TL, Werschmoeller D, Li X, Pfefferkorn FE, Duffie NA. Pulsed laser polishing of micro-milled Ti6Al4V samples. J Manuf Process 2009;11(2):74-81. https://doi. org/10.1016/j.jmapro.2009.10.001.

[7] Ossowska A, Zieliński A, Buczek M. Properties of surface layers of titanium alloy Ti6Al4V after laser melting processes. Adv Mater Sci 2010;10(4). https://doi.org/ 10.2478/v10077-010-0018-9.

[8] Balla VK, Soderlind J, Bose S, Bandyopadhyay A. Microstructure, mechanical and wear properties of laser surface melted Ti6Al4V alloy. J Mech Behav Biomed Mater 2014;32:335-44. https://doi.org/10.1016/j.jmbbm.2013.12.001

[9] Weerasinghe VM, West DRF, de Damborenea J. Laser surface nitriding of titanium and a titanium alloy. J Mater Process Technol 1996;58(1):79-86. https://doi.org/ 10.1016/0924-0136(95)02110-8.

[10] Kamat AM, Segall AE, Copley SM, Todd JA. Enhancement of CP-titanum wea resistance using a two-step $\mathrm{CO} 2$ laser-sustained plasma nitriding process. Surf Coating Technol 2017;325:229-38. https://doi.org/10.1016/j surfcoat.2017.06.030.

[11] Qu J, Blau PJ, Howe JY, Meyer III HM. Oxygen diffusion enables anti-wear boundary film formation on titanium surfaces in zinc-dialkyl-dithiophosphate (ZDDP)-containing lubricants. Scripta Mater 2009;60(10):886-9. https://doi.org/ 10.1016/j.scriptamat.2009.02.009.

[12] Bansal DG, Eryilmaz OL, Blau PJ. Surface engineering to improve the durability and lubricity of Ti-6Al-4V alloy. Wear 2011;271(9-10). https://doi.org/10.1016/ j.wear.2010.11.021. 2006-15.

[13] Nayar SK, Ikeuchi K, Kanade T. Surface reflection: physical and geometrical perspectives. IEEE Trans Pattern Anal Mach Intell 1991;13(7):611-34. https://doi. org/10.1109/34.85654.

[14] Seita M, Nimerfroh MM, Demkowicz MJ. Acquisition of partial grain orientation information using optical microscopy. Acta Mater 2017;123:70-81. https://doi. org/10.1016/j.actamat.2016.10.021.

[15] Nüsser C, Kumstel J, Kiedrowski T, Diatlov A, Willenborg E. Process- and materialinduced surface structures during laser polishing. Adv Eng Mater 2015;17(3): 268-77. https://doi.org/10.1002/adem.201400426.

[16] Redmore E, Li X, Dong H. Tribological performance of surface engineered low-cost beta titanium alloy. Wear 2019;426-427:952-60. https://doi.org/10.1016/j. wear.2019.01.032.

[17] Li X, Dong H. Ceramic conversion treatment of titanium-based materials. In: Dong H, editor. Surface engineering of light alloys: aluminum, magnesium and titanium alloys. Oxford, UK: Woodhead Publishing Limited; 2010. p. 475-500.

[18] Siva Rama Krishna D, Brama YL, Sun Y. Thick rutile layer on titanium for tribological applications. Tribol Int 2007;40(2):329-34. https://doi.org/10.1016/ j.triboint.2005.08.004

[19] Dong H, Bloyce A, Bell T. Slurry abrasion response of surface engineered Ti6Al4VELI. Tribol Int 1999;32(9):517-26. https://doi.org/10.1016/S0301-679X (99)00082-1.

[20] Oliver WC, Pharr GM. Measurement of hardness and elastic modulus by instrumented indentation: advances in understanding and refinements to methodology. J Mater Res 2004;19(1):3-20. https://doi.org/10.1557/ jmr.2004.19.1.3.
[21] Ahmed T, Rack HJ. Phase transformations during cooling in $\alpha+\beta$ titanium alloys. Mater Sci Eng, A 1998;243(1-2):206-11. https://doi.org/10.1016/S0921-5093 (97)00802-2.

[22] Lütjering G, Williams JC. Titanium. second ed. Berlin, Heidelberg: Springer; 2007.

[23] Yan M, Xu W, Dargusch MS, Tang HP, Brandt M, Qian M. Review of effect of oxygen on room temperature ductility of titanium and titanium alloys. Powder Metall 2014:57(4):251-7. https://doi.org/10.1179/1743290114Y.0000000108.

[24] Dong H, Li XY. Oxygen boost diffusion for the deep-case hardening of titanium alloys. Mater Sci Eng, A 2000;280(2):303-10. https://doi.org/10.1016/S09215093(99)00697-8.

[25] Okamoto H. O-Ti (Oxygen-Titanium). J Phase Equilibria Diffus 2011;32(5):473-4. https://doi.org/10.1007/s11669-011-9935-5.

[26] Hosseini SR, Ahmadi A. Evaluation of the effects of plasma nitriding temperature and time on the characterisation of Ti 6Al $4 \mathrm{~V}$ alloy. Vacuum 2013;87:30-9. https://doi.org/10.1016/j.vacuum.2012.06.008.

[27] Farè S, Lecis N, Vedani M, Silipigni A, Favoino P. Properties of nitrided layers formed during plasma nitriding of commercially pure Ti and Ti-6Al-4V alloy. Surf Coating Technol 2012;206(8-9):2287-92. https://doi.org/10.1016/j. surfcoat.2011.10.006.

[28] Leyland A, Matthews A. On the significance of the H/E ratio in wear control: a nanocomposite coating approach to optimised tribological behaviour. Wear 2000; 246(1-2):1-11. https://doi.org/10.1016/S0043-1648(00)00488-9.

[29] Bloyce A, Morton PH, Bell T. Surface engineering of titanium and titanium alloys. In: Cotell CM, Sprague JA, Smidt FA, editors. Surface engineering. ASM International; 1994. p. 835-51.

[30] Finlay WL, Snyder JA. Effects of three interstitial solutes (nitrogen, oxygen, and carbon) on the mechanical properties of high-purity, alpha titanium. J Occup Med 1950;2(2):277-86. https://doi.org/10.1007/BF03399001.

[31] Dabrowski R. The kinetics of phase transformations during continuous cooling of the Ti6Al4V alloy from the single-phase $\beta$ range. Arch Metall Mater 2011;56(3): 703-7. https://doi.org/10.2478/v10172-011-0077-x.

[32] Dong H, Bloyce A, Bell T. Design and the performance of a new titanium duplex surface engineering system. In: Gregory JK, Rack HJ, Eylon D, editors. Surface performance of titanium: proceedings of a symposium on surface performance of titanium 1996. Warrendale. Pa: Minerals Metals \& Materials Society; 1996. p. 23-31.

[33] Kessler O, Hoffmann F, Mayr P. The role of CVD parameters in producing the "eggshell" effect during the coating of steel. Chem Vap Depos 2000;6(5):253-9. https://doi.org/10.1002/1521-3862(200010)6:5<253::aid-cvde253>3.0.co;2-5.

[34] Dong H, Bell T. Enhanced wear resistance of titanium surfaces by a new therma oxidation treatment. Wear 2000;238(2):131-7. https://doi.org/10.1016/S00431648(99)00359-2.

[35] Molinari A, Straffelini G, Tesi B, Bacci T. Dry sliding wear mechanisms of the Ti6Al4V alloy. Wear 1997;208(1-2). https://doi.org/10.1016/S0043-1648(96) 07454-6. 105-12.

[36] Czichos H. The mechanism of the metallic adhesion bond. J Phys D: Appl Phys 1972;5(10):1890-7. https://doi.org/10.1088/0022-3727/5/10/321.

[37] Derjaguin BV, Smilga VP. Electronic theory of adhesion. J Appl Phys 1967;38(12): 4609. https://doi.org/10.1063/1.1709192.

[38] Buckley DH. The metal-to-metal interface and its effect on adhesion and friction. Invit. Lect. 1977:37-54. https://doi.org/10.1016/B978-0-12-404501-9.50012-2.

[39] Samsonov GV, Artamonov AY, Idzon IF. Interaction between the metal and the abrasive in Coulomb friction. Metall. Metal. Ceram. 1967;6(11):913-9. https://doi. org/10.1007/BF00773855.

[40] Jaffee RI, Campbell IE. The effect of oxygen, nitrogen, and hydrogen on iodide refined titanium. J Occup Med 1949;1(9):646-54. https://doi.org/10.1007/ BF03398910.

[41] Sob M, Kratochvíl J, Kroupa F. Theory of strengthening of alpha titanium by interstitial solutes. Czech J Phys 1975;25(8):872-90. https://doi.org/10.1007/ BF01589305.

[42] Conrad H. Effect of interstitial solutes on the strength and ductility of titanium. Prog Mater Sci 1981;26(2-4):123-403. https://doi.org/10.1016/0079-6425(81) 90001-3.

[43] Tyson WR. Solution hardening of titanium by oxygen. Scripta Metall 1969;3(12): 917-21. https://doi.org/10.1016/0036-9748(69)90241-5.

[44] Yu Q, Qi L, Tsuru T, Traylor R, Rugg D, Morris JW, et al. Origin of dramatic oxygen solute strengthening effect in titanium. Science 2015;347(6222):635-9. https:// doi.org/10.1126/science. 1260485 .

[45] Sargent GA, Conrad H. On the strengthening of titanium by oxygen. Scripta Metall 1972;6(11):1099-101. https://doi.org/10.1016/0036-9748(72)90196-2.

[46] Kwasniak P, Muzyk M, Garbacz H, Kurzydlowski KJ. Influence of oxygen content on the mechanical properties of hexagonal $\mathrm{Ti}$-first principles calculations. Mater Sci Eng, A 2014;590:74-9. https://doi.org/10.1016/j.msea.2013.10.004.

[47] Song Y, Guo ZX, Yang R. Influence of interstitial elements on the bulk modulus and theoretical strength of a-titanium: a first-principles study. Philos Mag A 2002;82 (7):1345-59. https://doi.org/10.1080/01418610208235676.

[48] Garg P, Bhatia MA, Solanki KN. Uncovering the influence of metallic and nonmetallic impurities on the ideal shear strength and ductility of Ti: an ab-initio study. J Alloys Compd 2019;788:413-21. https://doi.org/10.1016/j. jallcom.2019.02.231.

[49] Yang G, Liu Y, Hang Z, Xi N, Fu H, Chen H. Adhesion at cerium doped metalceramic $\alpha$-Fe/WC interface: a first-principles calculation. J Rare Earths 2019;37(7): 773-80. https://doi.org/10.1016/j.jre.2018.11.009. 
Karlsruher Institut für Technologie

\section{Repository KITopen}

Dies ist ein Postprint/begutachtetes Manuskript.

Empfohlene Zitierung:

Kümmel, D.; Linsler, D.; Schneider, R.; Schneider, J.

Surface engineering of a titanium alloy for tribological applications by nanosecond-pulsed laser.

2020. Tribology international, 150.

doi: $10.554 / I R / 1000119170$

Zitierung der Originalveröffentlichung:

Kümmel, D.; Linsler, D.; Schneider, R.; Schneider, J.

Surface engineering of a titanium alloy for tribological applications by nanosecond-pulsed laser.

2020. Tribology international, 150, Article no: 106376.

doi:10.1016/j.triboint.2020.106376 